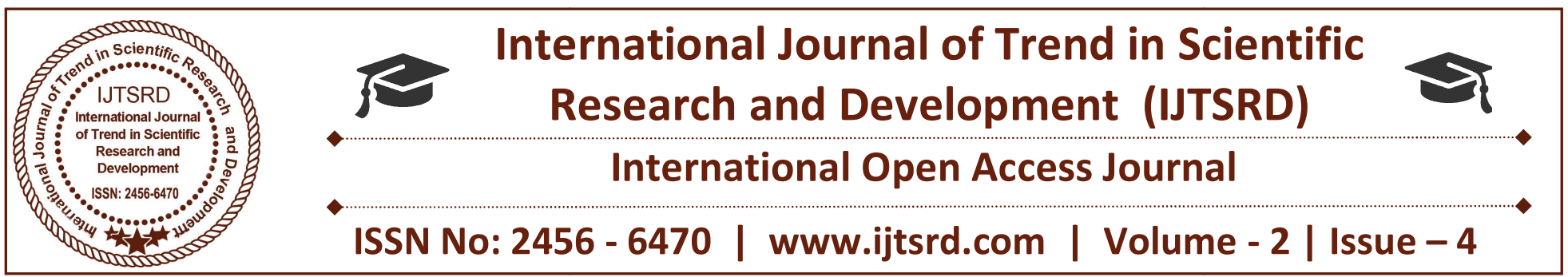

\title{
Improvement of a Radon Counter Sensitivity Using High-Voltage Ion Chamber
}

\author{
Chungyong Kim, Gyu-Sik Kim \\ Department of Electrical and Computer Engineering, University of Seoul, Seoul, Korea
}

\begin{abstract}
Radon is an invisible, odorless, and chemically inactive radioactive gas produced by the decay of uranium ore. Various types of equipment and components have been proposed for use in effective radon detection. In this paper, we used a radon counter with a PIN photodiode radon-sensor module. Using electrostatic collection and the PIN photodiode, a high sensitivity radon detector for air has been developed. The calibration system has also been developed using a linear regression analysis technique.
\end{abstract}

Keywords: radon, radon counter, PIN photodiode, electrostatic collection, high sensitivity, calibration system

\section{INTRODUCTION}

Radon is emitted almost everywhere on earth, but some geographical regions have a higher concentration than others do. Because inhaling radon and its radioactive-decay products causes irradiation of lung tissue, prolonged exposure to a high concentration of radon significantly increases the risk of developing cancer.

There are many commercial instruments and techniques available for measuring radon indoors. In [1], highly sensitive, electrostatic collection chambers using Columbia Resin 39 (CR-39) plastic track detectors were developed for measuring low-level radon. In [2], the unique characteristics and the shortcomings of track detectors for neutron and radon dosimetry is described and compared with those of alternative detector systems. In [3], low-cost alphaparticle sensor systems using special Positive Metal-
Oxide Semiconductor (PMOS) transistors in a floating n-well were developed for radon and radon-daughter monitoring and dosimetry. In [4], a radon detector employed an electrically charged, pressed, porous metal filter that permitted radon-gas diffusion while blocking ambient light. It readily trapped both attached and unattached Polonium-214 (Po-214) and Polonium 218 (Po-218) ions present in gas passing through the filter. The filter was positively charged relative to the unbiased $\mathrm{PN}$ junction of a photo-diode detector within a detection chamber. In [5], an alpha particle detector was designed using a commercial silicon photodiode. An application of a silicon photodiode detector for radon progeny measurements is presented in [6]. In [7], a high-sensitivity radon detector that uses an electrostatic collection and a PIN photodiode for air and water was developed. A calibration system for the humidity-dependence measurement has also been developed. In [8], The PIN photodiode radon detector was improved for the highly sensitive measurement of low-level radon concentrations. The system was shown to have a sensitivity to radon concentrations as low as $1.6 \mathrm{mBq} /$ $\mathrm{m}^{3}$.

For our experiments, we used a radon counter with a PIN photodiode radon-sensor module. Using electrostatic collection and the PIN photodiode, a high sensitivity radon detector for air has been developed. The calibration system has also been developed using a linear regression analysis technique.

\section{PIN Photodiode Radon Counter}

A commercial PIN photodiode can be used to detect radiation, and particularly, alpha particles. It is low 
cost, has good quantum efficiency, and good energy resolution. It can also work with a low bias voltage. A PIN photodiode is more widely used than a conventional photomultiplier tube (PMT) because it requires less biasing to operate and it is very compact. The PIN photodiode sensor module shown in Fig. 1 was used to detect radon gas in our tests.

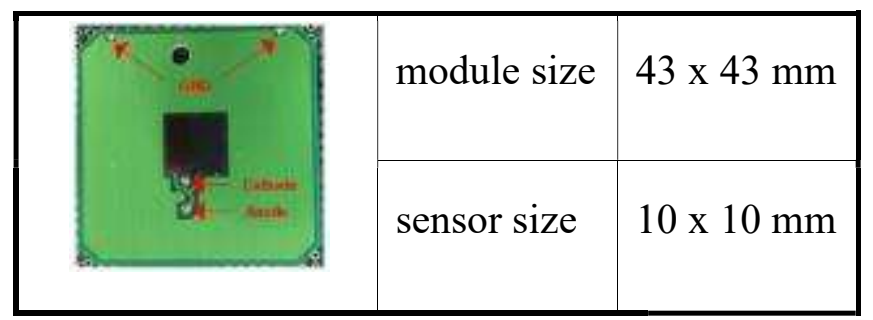

Fig. 1: PIN photodiode sensor module

The Mega 2560 is a microcontroller board based on the Atmega 2560. It has 54 digital input/output pins (of which 15 can be used as Pulse Width Modulation (PWM) outputs), 16 analog inputs, 4 UARTs (hardware serial ports), a $16 \mathrm{MHz}$ crystal oscillator, a USB port, a power jack, an in-circuit serial programming (ICSP) header, and a reset button. It contains everything needed to support the microcontroller; it just needs to be connected to a computer with a USB cable or powered with an ACto-DC adapter or battery.

A liquid crystal display (LCD) screen is an electronic display module found in a wide range of applications. The 16x2 LCD display, the most basic, most commonly used module is found in many different devices and circuits. These modules are preferred over the 7-segment and other multi-segment light-emitting diodes (LEDs) because LCDs are economical; easily programmable; and they have no limitations when it comes to displaying special characters, custom characters, and animations. A $16 \times 2$ LCD is a 16 character by two-line display. We used an LCD with a 5x7-pixel matrix in our experiments. The LCD has two registers: Command and Data. The Command register stores the instructions sent to the LCD. A command is an instruction sent to the LCD telling it to perform a predefined task, such as initializing the screen, clearing the screen, setting the cursor position, controlling the display, etc. The Data register stores the data to be displayed on the LCD. The LCD display shown in Fig. 3 is an LCD module (BC4915AYPLEH) that shows the level of radon gas in $\mathrm{pCi} / \mathrm{L}$. The display range is from 0.0 to 999.9 . The radon counter we developed was designed to notify a user of the level of radon gas. It is updated every hour that there is a change in the level of radon gas.
Using the circuit designs for the power, high voltage generator, LCD, switch, LED, buzzer, microprocessor control unit (MCU), and sensor circuit, we assembled the PIN photodiode radon counter shown in Fig. 2.

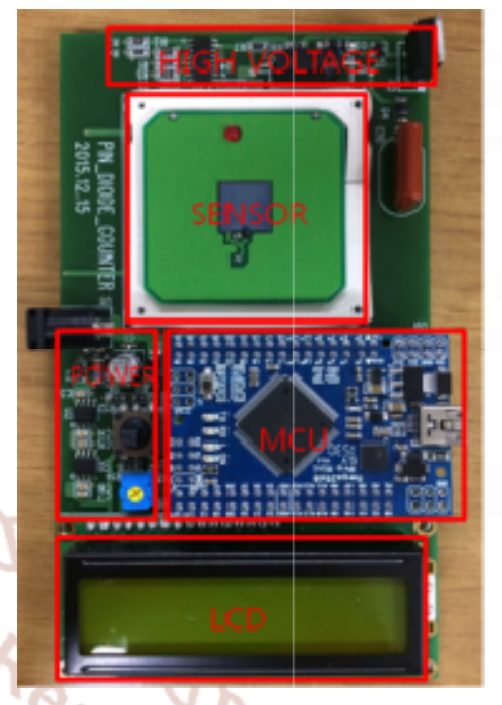

Fig. 2: Assembled PIN photodiode radon counter III. Sensitivity Improvement Using a High
Voltage Power Module In [7], a high-sensitivity radon detector that uses an electrostatic collection and a PIN photodiode for air and water was developed.

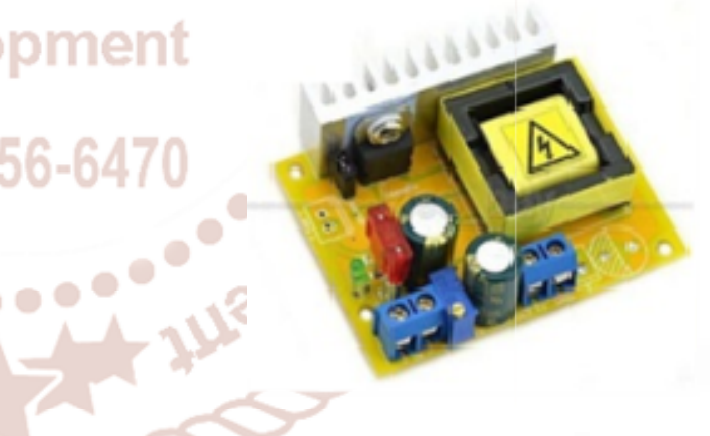

Fig. 3: High voltage power module

The high voltage power module shown in Fig. 3 which can generate a high voltage up to $390 \mathrm{~V}$ was used to test the sensitivity improvement of our developed radon counter. Fig. 4 shows the radon counter connected with a high voltage power module. Fig. 5 shows the experimental set-up for sensitivity test according to various voltages. 
International Journal of Trend in Scientific Research and Development (IJTSRD) ISSN: 2456-6470

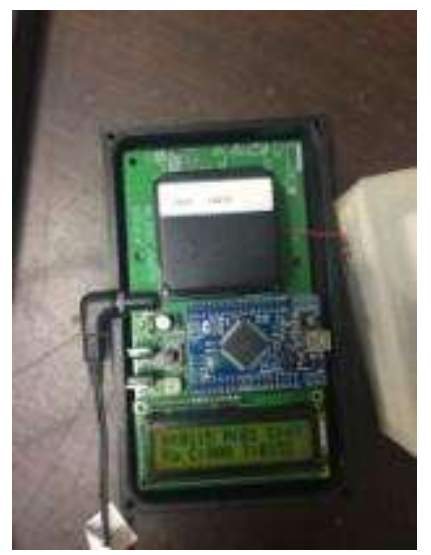

\section{Calibration Using a Linear Regression Analysis}

The methyl methacrylate box was made for radon concentration calibration as shown in Fig. 7. The calibration experiment was done for 72 hours for varied concentration of radon gas. Using RAD7, the implemented PIN photodiode radon counter could be calibrated as shown in Fig. 8. Fig. 8 shows the linear regression analysis for 12 hours data average. $\mathrm{R}^{2}$ was 0.818 in Fig. 8.

Fig. 4: Radon counter connected with a high voltage power module

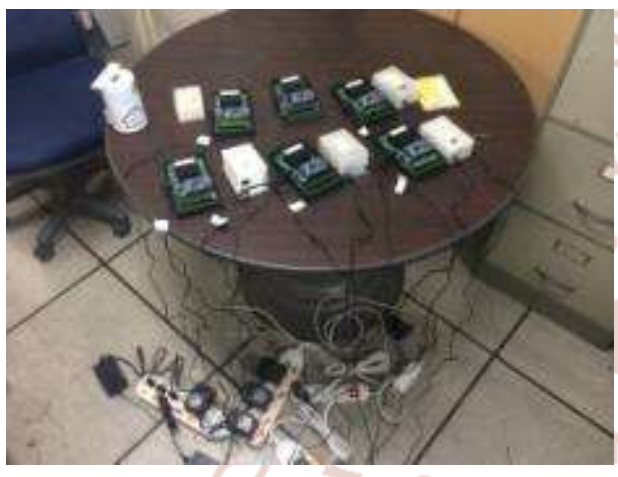

Fig 5: Experimental set-up for sensitivity test

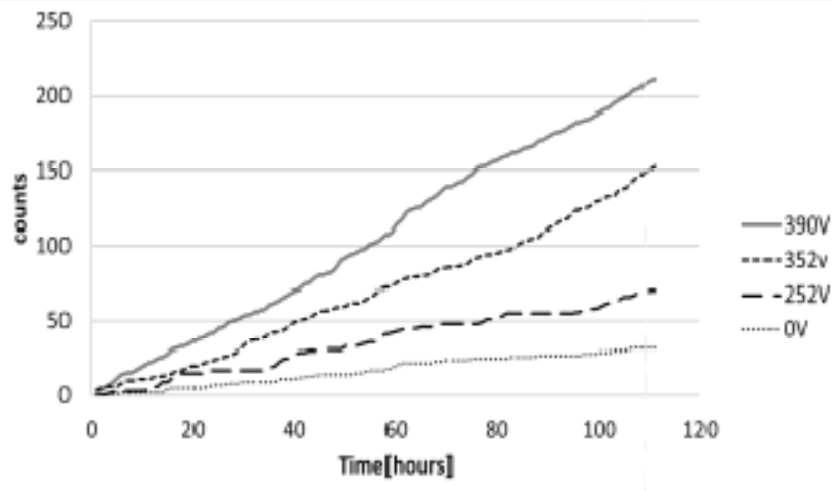

Fig 6: Experimental results of sensitivity test for various voltages

Fig. 6 shows the experimental results of sensitivity test for various voltages. As can be seen from Fig. 6, we could get 210 radon counts in 110 hours for a high voltage of $390 \mathrm{~V}$. We also got $150,70,30$ radon counts in 110 hours for $352 \mathrm{~V}, 252 \mathrm{~V}, 0 \mathrm{~V}$, respectively.

These experimental results show that the ion chamber applied with a high voltage could make the developed radon counter highly sensitive.

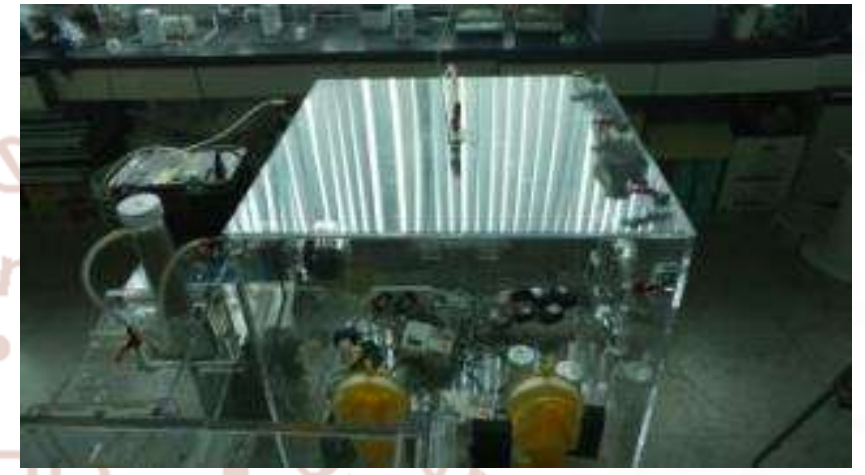

Fig. 7: Experimental set-up for calibration
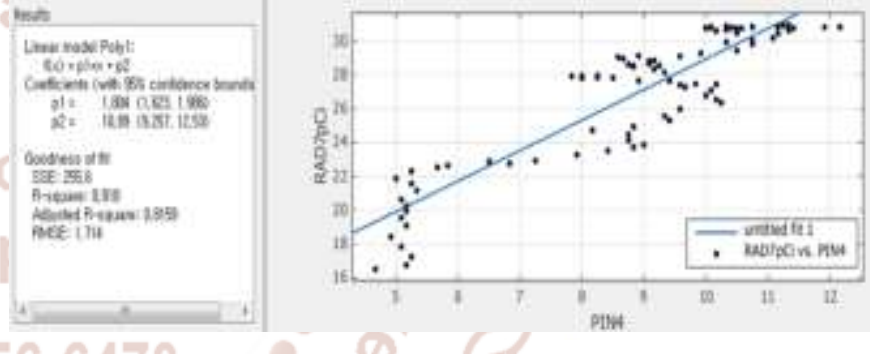

Fig. 8: Linear regression analysis for radon concentration calibration

\section{CONCLUDING REMARKS}

In this paper, a radon counter using a PIN photodiode radon-sensor module was discussed. For our experiments, we used a radon counter with a PIN photodiode radon-sensor module. Using electrostatic collection and the PIN photodiode, a high sensitivity radon detector for air has been developed. The calibration system has also been developed using a linear regression analysis technique. This radon counter can be used to measure radon concentration of the indoor air in houses and workplaces.

\section{ACKNOWLEDGMENT}

This work was also supported by the National Research Foundation of Korea (NRF) grant funded by the Korea government (MSIP) (No. 2016011249). 


\section{REFERENCES}

1. Hiroshi Miyake, Keiji Oda and Masami Michijima, "Portable and high-sensitive apparatus for measurement of environmental radon using CR-39 track detector," Japanese Journal of Applied Physics, Vol.26, No.4, pp.607-610, April, 1987

2. L. Tommasino, "Importance of track detectors in radiation dosimetry," Nucl. Tracks Radiat. Meas., Vol.22, No.1-4, pp.707-717, 1993

3. T. Streil, R. Klinke, W. Birkholz, and G. Just, "New alpha radiation detection systems for radon and radon daughter monitoring," Radiation Measurements, Vol.25, No.1-4, pp.621-622, 1995

4. Peter J. Diamondis, "Radon gas measurement apparatus having alpha particle-detecting photovoltaic photodiode surrounded by porous pressed metal daughter filer electrically charged as PO-219 ion accelerator," US patent, P.N. 5489780, Feb. 1996
5. A. Chambaudet, D. Klein, and M. Voytchev, "Study of the response of silicon detector for alpha particles," Radiation Measurements, Vol.28, No.1-6, pp.127-132, 1997

6. M. Voytchev, D. Klein, A. Chambaudet, G. Georgiev, and M. Iovtchev, "Applications of a silicon photodiode detector for radon progeny measurements," Radiation Measurements, Vol.31, pp.375-378, 1999

7. Y. Takeuchi, K. Okumura, T. Kajita, S. Tasaka, H. Hori, M. Nemoto, and H. Okazawa, "Development of high sensitivity radon detectors," Nuclear Instruments \& Methods in Physics Research A 421, pp.334-341, 1999

8. E. Choi, et al., "Highly sensitive radon monitor and radon emanation rates for detector components," Nuclear Instruments \& Methods in Physics Research A 459, pp.177-181, 2001 